Supplement of Clim. Past Discuss., 11, 5203-5241, 2015

http://www.clim-past-discuss.net/11/5203/2015/

doi:10.5194/cpd-11-5203-2015-supplement

(C) Author(s) 2015. CC Attribution 3.0 License.

(c) (i)

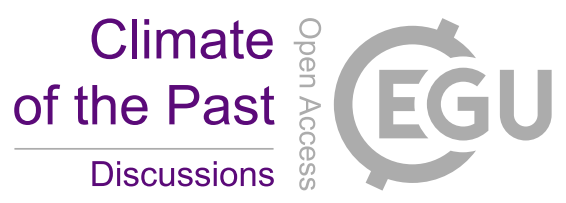

Supplement of

\title{
The impact of the North American ice sheet on the evolution of the Eurasian ice sheet during the last glacial cycle
}

\author{
J. Liakka et al. \\ Correspondence to: J. Liakka (johan.liakka@senckenberg.de)
}

The copyright of individual parts of the supplement might differ from the CC-BY 3.0 licence. 
a. PI OHT JFM

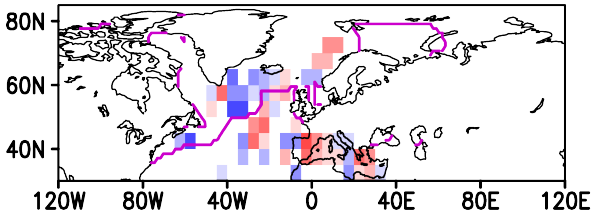

c. LGM OHT JFM

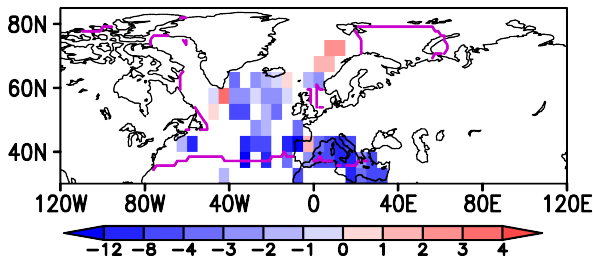

b. PI OHT JAS

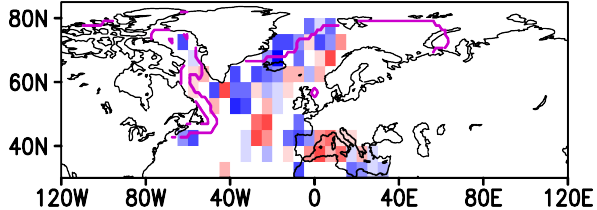

d. LGM OHT JAS

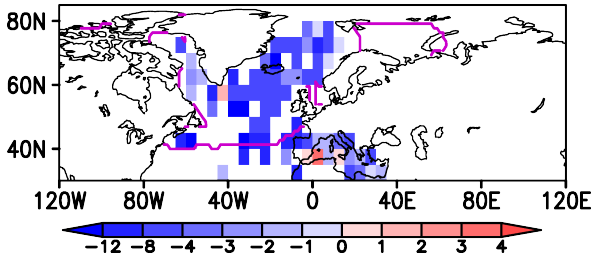

Figure 1. The shading displays the difference (in ${ }^{\circ} \mathrm{C}$ ) between the simulated SST anomalies (the difference between the fullGlacial LGM simulation and the pre-industrial simulation in Löfverström et al. 2014) and the LGM SST anomalies from the Multiproxy Approach for the Reconstruction of the Glacial Ocean Surface (MARGO; Margo Project Members et al., 2009) for the simulations with PI OHT (a,b) and LGM OHT (Brandefelt and Otto-Bliesner. 2009) (c,d). Panels (a,c) show the model-proxy difference in the boreal winter (January-March), and (b,d) in the summer (July-September). Red (blue) shading indicates that the model response for LGM is warmer (colder) than the proxy. The purple contour depicts the position of the simulated sea-ice margin. Note that the LGM OHT simulations yield too cold conditions in the North Atlantic in both the summer and winter seasons.

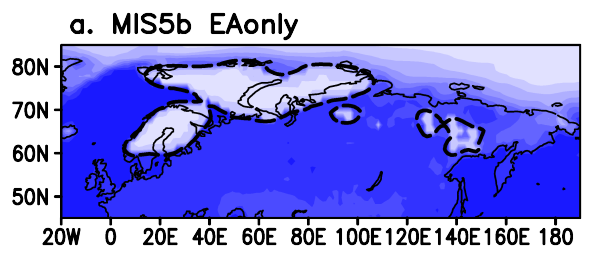

b. MIS5b fullGlacial-EAonly

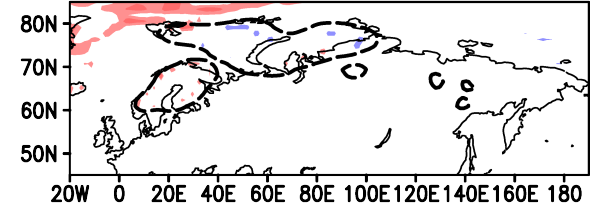

c. MIS4 EAonly

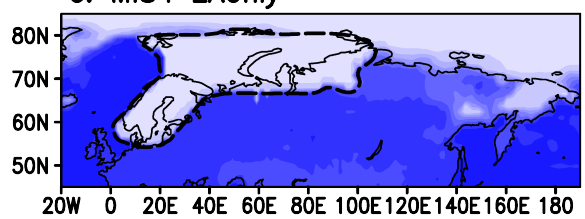

d. MIS4 fullGlacial-EAonly

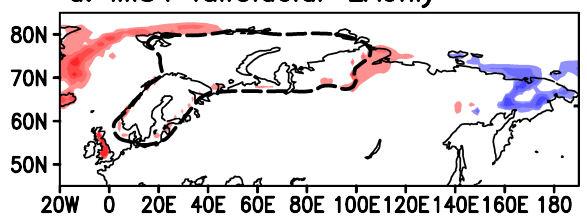

e. LGM EAonly
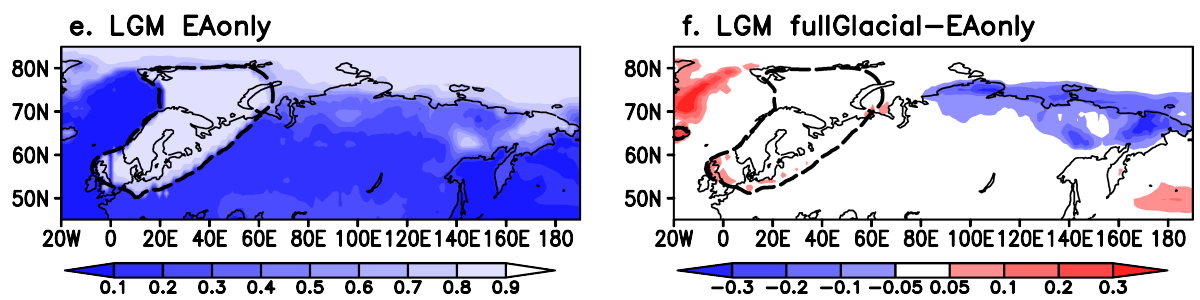

Figure 2. The JJA (June-August) surface albedo in Eurasia from the EAonly simulations (a,b,e), and JJA surface albedo anomalies induced by the North American ice sheet (the difference between fullGlacial and EAonly simulations; b,d,f) for MIS5b (a,b), MIS4 (c,d) and LGM (e,f). 
a. MIS5b EAonly

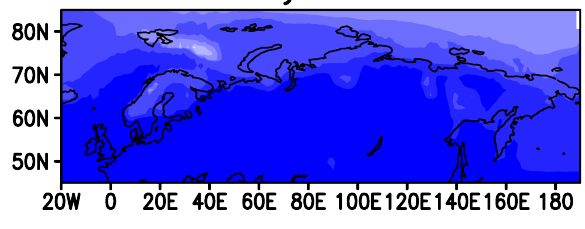

c. MIS4 EAonly

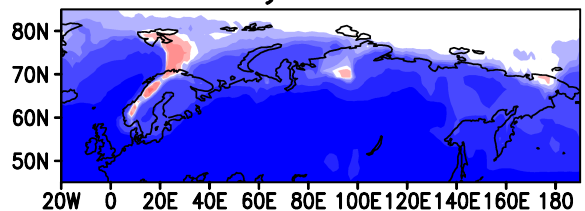

e. LGM EAonly

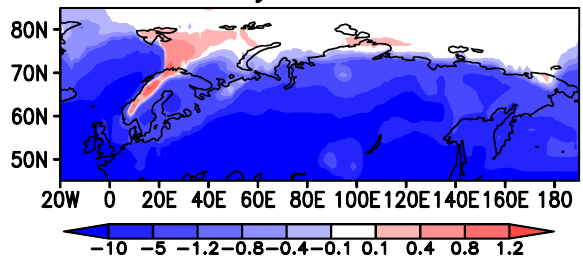

b. MIS5b fullGlacial

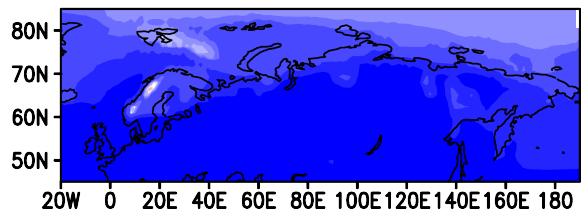

d. MIS4 fullGlacial

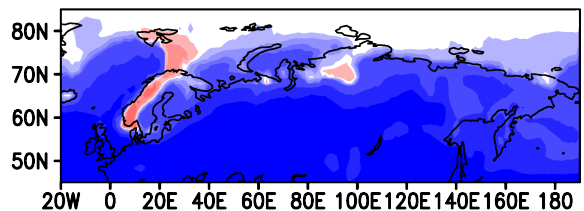

f. LGM fullGlacial

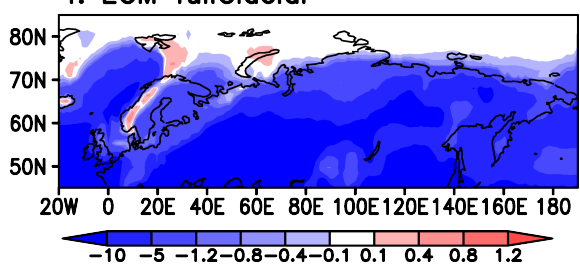

Figure 3. The initial surface mass balance in Eurasia (in $\mathrm{m} \mathrm{yr}^{-1}$ ) derived from the EAonly (a,c,e) and fullGlacial (b,d,f) simulations ofMIS5b (a,b), MIS4 (c,d) and LGM (e,f).

a. MIS5b EAonly

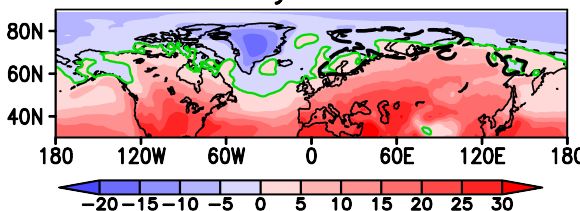

c. MIS4 EAonly

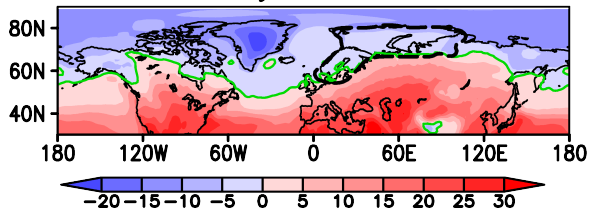

e. LGM EAonly

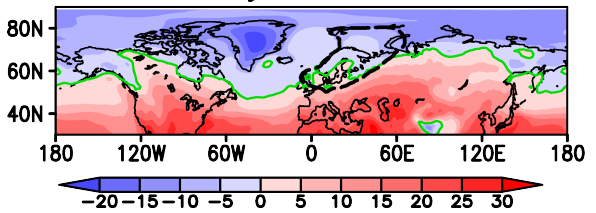

b. MIS5b fullGlacial-EAonly

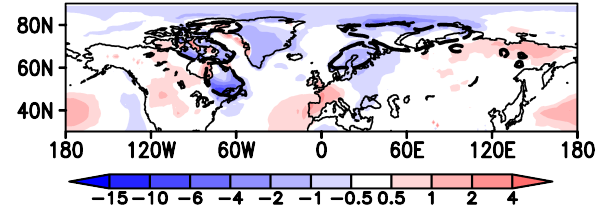

d. MIS4 fullGlacial-EAonly

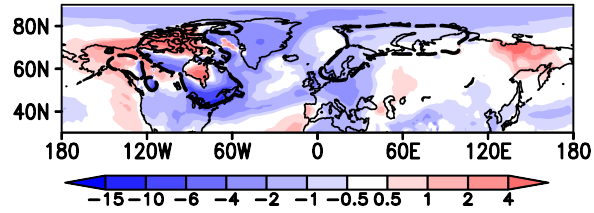

f. LGM fullGlacial-EAonly

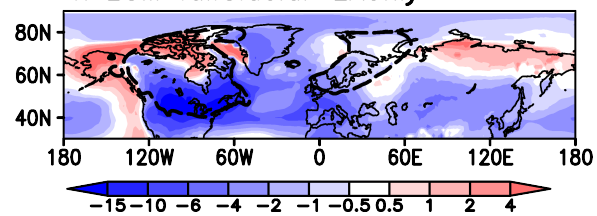

Figure 4. JJA surface temperature: same as Fig. 2c-h in the main paper, but with LGM OHT. 
a. MIS5b EAonly

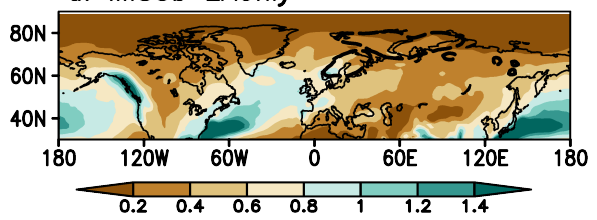

c. MIS4 EAonly

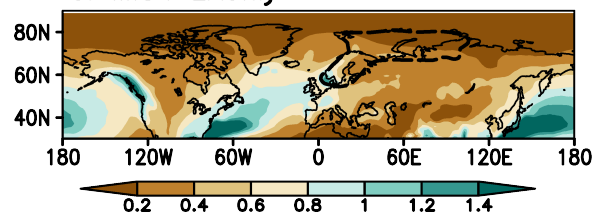

e. LGM EAonly

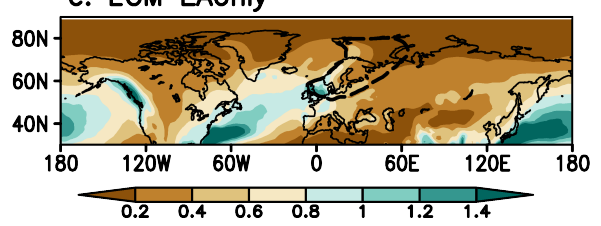

b. MIS5b fullGlacial-EAonly

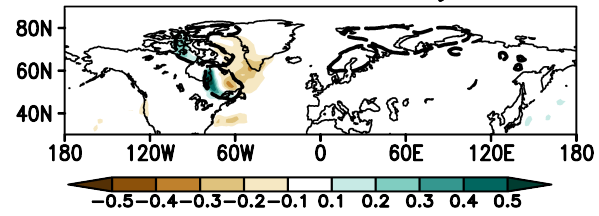

d. MIS4 fullGlacial-EAonly

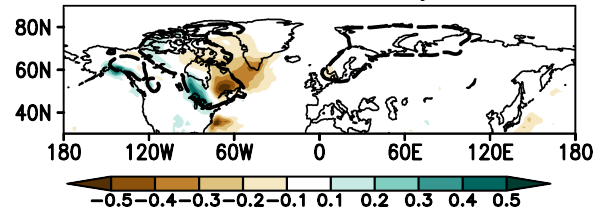

f. LGM fullGlacial-EAonly

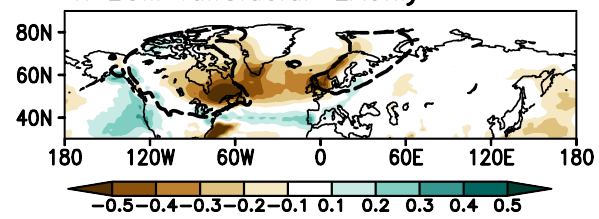

Figure 5. Annual precipitation: same as Fig. 3c-h in the main paper, but with LGM OHT.

a. MIS5b EAonly
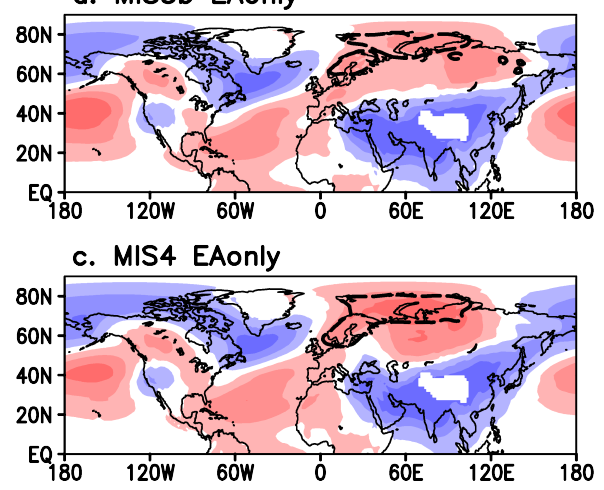

e. LGM EAonly

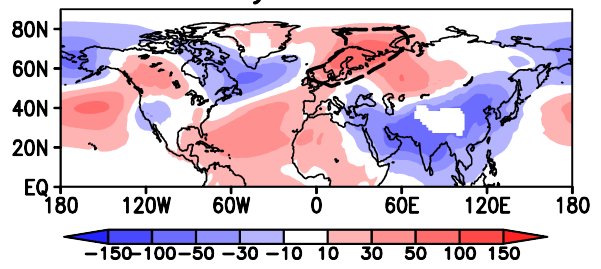

b. MIS5b fullGlacial-EAonly

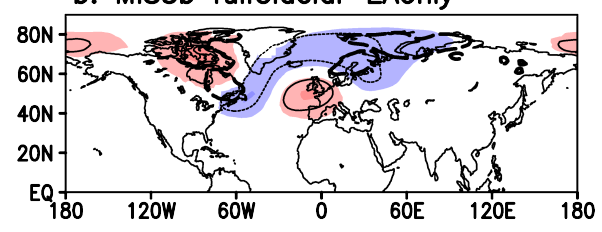

d. MIS4 fullGlacial-EAonly

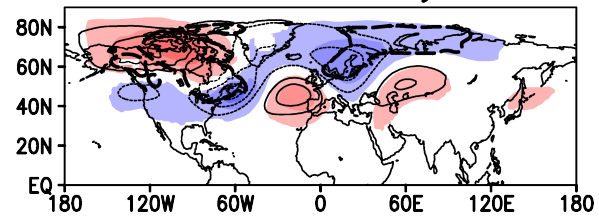

f. LGM fullGlacial-EAonly

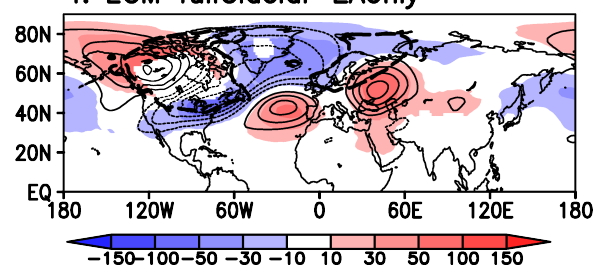

Figure 6. $700 \mathrm{hPa}$ (shading) and $300 \mathrm{hPa}$ (contours) geopotential height anomalies (zonal mean subtracted): same as Fig. 4c-h in the main paper, but with LGM OHT. 


\section{References}

Brandefelt, J. and Otto-Bliesner, B. L.: Equilibration and variability in a Last Glacial Maximum climate simulation with CCSM3, Geophys. Res. Lett., 36, L19712, doi 10.1029/2009GL040364 2009.

Löfverström, M., Caballero, R., Nilsson, J., and Kleman, J.: Evolution of the large-scale atmospheric circulation in response to changing ice sheets over the last glacial cycle, Climate of the Past, 10, 1453-1471, doi $10.5194 / \mathrm{cp}-10-1453-2014,2014$.

Margo Project Members, Waelbroeck, C., Paul, A., Kucera, M., Rosell-Melé, A., Weinelt, M., Schneider, R., Mix, A. C., Abelmann, A., Armand, L., Bard, E., Barker, S., Barrows, T. T., Benway, H., Cacho, I., Chen, M.-T., Cortijo, E., Crosta, X., de Vernal, A., Dokken, T., Duprat, J., Elderfield, H., Eynaud, F., Gersonde, R., Hayes, A., Henry, M., Hillaire-Marcel, C., Huang, C.-C., Jansen, E., Juggins, S., Kallel, N., Kiefer, T., Kienast, M., Labeyrie, L., Leclaire, H., Londeix, L., Mangin, S., Matthiessen, J., Marret, F., Meland, M., Morey, A. E., Mulitza, S., Pflaumann, U., Pisias, N. G., Radi, T., Rochon, A., Rohling, E. J., Sbaffi, L., Schäfer-Neth, C., Solignac, S., Spero, H., Tachikawa, K., and Turon, J.-L.: Constraints on the magnitude and patterns of ocean cooling at the Last Glacial Maximum, Nature Geoscience, 2, 127-132, doi 10.1038/ngeo411 2009. 